\title{
Creatine Supplementation in the Elderly: is Resistance Training Really Needed?
}

\section{Moon $\mathrm{A}^{1}$, Heywood $\mathrm{L}^{1}$, Rutherford $\mathrm{S}^{1}$ and Cobbold $\mathrm{C}^{*_{2}}$}

${ }^{1}$ School of Biosciences, Cardiff University, Museum Avenue, Cardiff CF11 3AX, United Kingdom

${ }^{2}$ Institute of Science and the Environment, Worcester University, Henwick Grove, Worcester WR2 6AJ, UK

${ }^{*}$ Corresponding author: Cobbold C, Institute of Science and the Environment, Worcester University, Henwick Grove, Worcester WR2 6AJ, UK, E-mail: c.cobbold@worc.ac.uk

Citation: Moon A, Heywood L, Rutherford S, Cobbold C (2015) Creatine Supplementation in the Elderly: is Resistance Training Really Needed? J Nutr Health Sci 2(2): 203. doi: 10.15744/2393-9060.2.203

Received Date: December 03, 2014 Accepted Date: May 19, 2015 Published Date: May 21, 2015

\begin{abstract}
Introduction: Decreases in muscle mass, strength and power are associated with ageing, all of which increase the risk of falls, and cause a loss of independence. Creatine supplementation is often used in younger athletes to improve anaerobic performance, power and strength, however the potential benefits of creatine supplementation in older individuals are less clear.

Aim: This review assesses the current literature on whether creatine supplementation in the presence of resistance training enhances physical performance in older adults above and beyond those undertaking resistance training alone or only taking creatine supplements.

Results: Whilst reports are conflicting, there is good evidence to suggest that creatine supplementation with resistance training increases muscular endurance, lower body strength and lean body mass; this is above results obtained with creatine supplementation or resistance training alone. The increased muscle mass observed with training has previously been shown to lead to increased bone mineral content and an associated reduced fracture risk; however, the additional benefits of creatine supplementation on this are less clear, and more work is needed to confirm whether exogenously taken creatine will benefit bone mineral density.

Conclusion: Creatine supplementation in the elderly may lead to increased muscle mass, endurance and performance, and those who undertake resistance training may show further improvements with creatine supplementation. However, for elderly subjects who do not partake in resistance training, creatine supplementation offers significant improvements in increasing muscular mass and strength, and increasing their quality of life, whilst these benefits are lower on the whole than those who undertake regular resistance training.

Keywords: Ageing; Creatine; Elderly; Supplementation; Resistance training
\end{abstract}

\section{Introduction}

With an ageing population comes age-related losses in skeletal muscle mass, sarcopenia and associated risks of falls, morbidity and mortality. Importantly many older individuals still regularly perform aerobic and resistance training which serves to maintain this muscle mass and reduce these risks however a large proportion do not partake in regular exrecise [1]. There is evidence that creatine supplementation may maintain muscle mass and function in older adults [2], but an important question is whether resistance training and creatine supplementation have an additive effect on muscle structure and function or can older adults receive the same degree of benefit by just partaking in one of these protocols?

\section{Creatine}

Creatine is important for energy metabolism, and is thought to be an effective ergogenic aid in physical performance [3]. Creatine is synthesised within the body and ingested naturally from meat [3] or artificially through supplements. $94 \%$ of total body creatine is located in skeletal muscles and is stored as either free (40\%) or phosphorylated creatine (PCr; 60\%) [4].

Within skeletal muscles, creatine is hypothesised to shuttle high energy phosphogens between the mitochondria and cytosol [5], increasing the efficiency of cross-bridge cycling and thereby enhancing skeletal muscle contraction (Figure 1). Firstly, ATP synthesised in the mitochondrial matrix is transported via creatine kinase (CK) to the mitochondrial intermembrane space where $\mathrm{CK}$ catalyses the formation of ADP and PCr; Figure 2 reveals the equation from which ATP is then generated from stores of PCr via creatine kinase during periods of intense exercise. The ADP produced is transported back to the matrix where it is rephosphorylated when required. Liberated PCr migrates to the cytosol to sites of ATP consumption, where local CK enzymes regenerate ATP to allow for increased contraction. The liberated creatine then diffuses back to the mitochondria to allow for subsequent phosphorylation if required. This "transport" process is thought to occur in endurance-type activities [6-8]. Creatine supplementation has been shown to increase PCr regeneration [9], increasing ATP availability, thus facilitating prolonged physical activity [4]. 


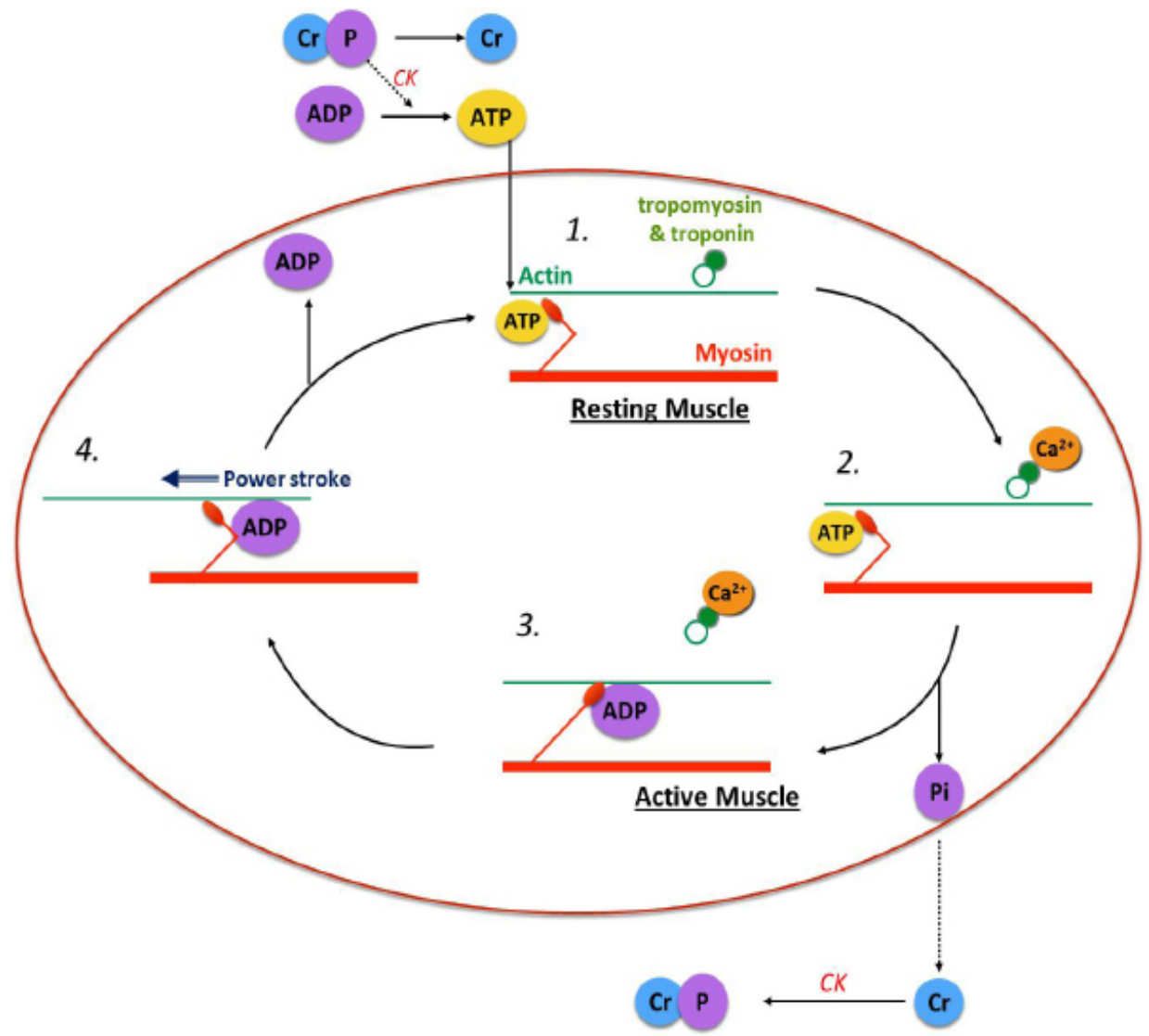

Figure1: Schematic diagram showing the mechanism leading to muscle contraction. Contraction occurs when skeletal muscle fibres are activated by motor neurones. An impulse arrives by motor neurone and is transmitted via neuromuscular junction to the skeletal muscle fibre, before travelling along transverse tubules to the sarcoplasmic reticulum, which releases calcium ions into resting muscle cells (1). Resistance training can increase this neuromuscular capacity. The release of calcium ions triggers the interaction of actin and myosin filaments (2) by binding to troponin and causing a conformational change which causes tropomysosin being physically moved aside to uncover cross-bridge binding sites on the actin filaments (3), which myosin binds to pull the actin towards the centre of the sarcomere (power stroke) (4), which is powered by ATP hydrolysis. Creatine can increase the efficiency of this system by shuttling the phosphogens between the mitochondria and cytosol. Creatine kinase catalyses PCr and ADP formation in the mitochondrial matrix, allowing PCr to migrate to sites of ATP consumption, for example, in vigorous exercise, where local CK enzymes regenerate ATP (5) for increased muscular contraction. Resistance training is thought to also increase the efficiency of this system. (Adapted from [52])

\section{$\mathrm{Cr}+\mathrm{ATP} \rightleftarrows \mathrm{PCr}+\mathrm{ADP}+\mathrm{H}^{+}$}

Figure2: Creatine kinase catalyses the reversible reaction between creatine (Cr) and ATP to form the energy store, phosphocreatine (PCr). PCr is produced when ATP levels are high during low rates of muscular activity. PCr is then utilised when the more limited intramuscular supply of ATP is depleted during anaerobic exercise; the phosphate is transferred from PCr to ADP, to replenish ATP, a key cellular energy carrying molecule. Intramuscular supplies of PCr and ATP are limited and the combined total is estimated to sustain high-intensity exercise for approximately 10 seconds [4]

Creatine is now the most commonly used dietary supplement for sports, especially those involving repeated short explosive anaerobic activities $[3,4,10,11]$. Users of creatine range from elite athletes to recreational exercisers, although its use is more frequent and more commonly studied in younger adults. There are a number of different loading programmes in use and the most common involves an initial loading phase of $20 \mathrm{~g} /$ day for 5-7 days, followed by a maintenance phase of 3-5 g/day for longer periods of 1-6 months [3].

An increase in body mass is a commonly reported effect of creatine supplementation [12]. This may be attributed to increased muscular water content; creatine is believed to induce an osmotic loading effect in muscle cells $[13,14]$. This osmotic loading effect has been suggested to increase protein synthesis and decrease the rate of protein degradation $[3,5]$ thereby increasing muscle mass. However, the mechanism by which it does so is not confirmed. It has been suggested that the anabolic signal triggered by this increase in osmolarity may increase the expression of MRF4 or other myogenic transcription factors which up regulate muscle 
specific genes [15]. It has been shown that creatine supplementation increased MRF4 in young healthy adults during a 10 week training regime [16]. Another potential mechanism for creatine's action concerns increasing satellite cell mitotic activity, which may also increase mRNA transcription of myogenic factors and subsequent muscle protein synthesis [17]. It is interesting to note that resistance training has been shown to increase both satellite cells and myogenic regulatory factors [18], with one study reporting a 31\% increase in satellite cell content following a 90 day training protocol [19]. These results also correspond with an increase in both muscle mass and strength. This suggests that satellite cell recruitment and subsequent myogenic transcriptional factor activation are mechanisms by which resistance training and creatine supplementation may exhibit their function. In age, satellite cells gradually decline [20], thus enhancing activity of the remaining population may be advantageous in elderly individuals for maintaining muscle function.

\section{Sarcopenia}

Sarcopenia is the age-related loss of muscle mass, strength and function which ultimately leads to a decline in physical performance and increased morbidity and mortality [1]. The mechanisms that cause sarcopenia are not fully understood, however the decline of alpha-motor neuronal input to muscle is thought to be heavily involved [21]. This can lead to a decrease in protein synthesis and a reduction of muscle fibre quantity and quality [1,22]. In addition to sarcopenia, old age is associated with decreases in bone density and mineral content leading to an increased risk of osteoporosis and associated fractures [23]. These changes can lead to reduced physical performance, with increased risk of falls [1]. Ultimately, the elderly suffer a loss of independence.

Resistance training is thought to be a good intervention of sarcopenia, through increasing strength and size of muscles [1], via Type I and IIa muscle fibre hypertrophy due to motor unit recruitment [15]. Furthermore, resistance training can increase mitochondrial capacity in skeletal muscles, significant as mitochondrial impairment is often seen in older adults and contributes to muscle weakness [24]. Creatine ingestion has been shown with young athletes to further enhance these beneficial effects seen with resistance training [25]. Therefore, it has been proposed that those with a reduced muscular strength and performance may be treated with creatine supplementation, such as those suffering from age-related disorders such as sarcopenia. Creatine supplementation has few adverse effects confirmed [26], and thus may be both a safe and economical treatment option for elderly subjects.

However, it is not yet clear if resistance training and creatine supplementation can benefit the older generation over and above just the ingestion of exogenous creatine. Therefore, the aim of this literature analysis was to determine the effects of creatine supplementation with associated resistance training on muscular strength and function, bone density and mineral content in the older adult, and to assess whether any increases in physical performance with creatine supplementation can improve functional capacity, and subsequently prolong independent living.

\section{The effect of resistance training and/or creatine on upper and lower body strength}

While studies have consistently shown that resistance training is an effective method for the promotion of muscle strength and fat free mass [27], recent interest has shown that creatine supplementation can also give benefits [2]. Intramuscular creatine concentrations are reported to be lower in older adults than younger ones [28], and it has also been demonstrated that people with lower intramuscular total creatine concentrations have an accentuated ability to increase intracellular creatine content following supplementation [29]. Therefore, older adults may show improvements more from a combination of strength training and creatine supplementation than either alone. Table 1 shows the main protocols used to assess changes in muscular strength and endurance and Table 2 summarises the main findings of resistance training in the presence of creatine supplementation on muscular strength, power, and body composition.

Tarnopolsky et al. (2007) showed significant increases in upper body muscle strength following a programme of creatine and conjugated linoleic acid supplementation alongside resistance training, with improvements observed in both chest press and arm flexion [30]. In contrast to this, Chrusch et al. (2001) and Candow et al. (2008) demonstrated no improvements in upper body maximal strength, following protocols of resistance training with creatine supplementation [31,32]. Chrusch et al. (2001) suggested a possible explanation for their lack of improvement was the initial higher level of upper body strength in the creatine group compared with placebo [32], thus the creatine group possibly had smaller potential for improvement. The lack of improvement in Candow et al. (2008) could possibly be due to the low 15g per week dosage of creatine used compared to other studies [31]. Intriguingly, this study demonstrated that creatine in combination with protein supplementation significantly enhanced upper body strength compared to creatine alone or the placebo [31]; it has been reported that amino acid ingestion following exercise can enhance the ratio of protein synthesis to protein degradation [33]. Furthermore, this study showed that creatine significantly reduced muscle protein degradation and enhanced muscle thickness [33]. More recently, Gualano et al (2014) divided participants into four groups: a group taking creatine, a resistance trained group, a group supplementing creatine alongside training, as well as a placebo group. They demonstrated upper limb strength being significantly increased when creatine supplementation was added to resistance training in comparison to all other groups [34], and interestingly, it was reported that the number of subjects suffering from sarcopenia were reduced in the creatine supplementation groups, with and without exercise, in comparison to placebo groups [34]. This suggests that creatine supplementation alone may be beneficial in reducing muscle loss, even without exercise. 


\begin{tabular}{|c|c|c|}
\hline Type of muscular strength & Assessment xercise & Protocol \\
\hline \multicolumn{3}{|l|}{ Upper-body strength } \\
\hline Dynamic & $\begin{array}{l}\text { Bench press }(\mathrm{kg}) \\
\text { Chest press }(\mathrm{kg})\end{array}$ & $\begin{array}{l}\text { 1-reptition maximum }(1-\mathrm{RM})=\text { maximum amount of weight subject is able } \\
\text { to lift in a single repetition }\end{array}$ \\
\hline Isometric & Arm flexion (Nm) & $\begin{array}{l}\text { Maximum force generated by voluntary contraction of elbow flexors as } \\
\text { measured by strain gauge }\end{array}$ \\
\hline \multicolumn{3}{|l|}{ Lower-body strength } \\
\hline Dynamic & Leg press $(\mathrm{kg})$ & $\begin{array}{l}\text { 1-reptition maximum }(1-\mathrm{RM})=\text { maximum amount of weight subject is able } \\
\text { to press in a single repetition }\end{array}$ \\
\hline Isometric & $\begin{array}{l}\text { Knee extension and flexion } \mathrm{Nm}) \\
\text { Ankle dorsiflexion }(\mathrm{Nm})\end{array}$ & $\begin{array}{l}\text { Maximum voluntary contraction of knee and ankle flexors/extensors as } \\
\text { measured by strain gauge }\end{array}$ \\
\hline \multicolumn{3}{|l|}{ Muscular endurance } \\
\hline & $\begin{array}{l}\text { Repetitions of any of the above } \\
\text { exercises at a specified load }\end{array}$ & Maximum number of 1-RM a subject can repeat for the bench/leg/chest press \\
\hline \multicolumn{3}{|l|}{ Functional performance } \\
\hline & Tandem gait & Ability to walk in a straight line, touching heel to toe with every step \\
\hline & Timed sit to stand & Number of completed sit-stand repetitions within 30 s \\
\hline & Stair climb (s) & $\begin{array}{l}\text { Time taken and ability to climb a pre-determined flight of stairs without } \\
\text { assistance }\end{array}$ \\
\hline & Chair rise and walk (s) & Time taken to stand and walk a pre-determined distance \\
\hline
\end{tabular}

Table1: Summary of the main assessment protocols used to analyse muscular strength, endurance and general functional performance. Numerous assessment protocols were used for measuring strength, endurance and power. Commonly used methodologies are described below

Lower body maximal strength is critical for the independent mobility of the elderly. If creatine supplementation can further enhance or mimic training effects on lower extremity strength, it could potentially reduce risk of falls, a major cause of disability in the elderly [35]. Two studies showed evidence which supports the use of creatine supplementation enhancing lower body strength and power with associated training $[32,36]$. Chrusch et al. (2001) observed significant increases in lower limb strength following twelve weeks of creatine supplementation and resistance training in healthy older men [32]. Brose et al. (2003) reported positive improvements in isometric strength, although their results for significantly improved ankle dorsiflexion appeared to be confined to males [36]. Furthermore, these improvements in strength were not seen in all studies following similar protocols (Table 2). Although Bermon et al. (1998) reported no significant improvements, the creatine supplementing group experienced greater increases in leg press $(+7.0 \%)$ and leg extension (+1.9\%) compared with placebo [37]. In addition, Tarnopolsky et al. (2007) may have observed more significant results if the number of resistance sessions per week was increased from 2 to 3 sessions; however, older individuals may not be able to complete regular resistance training sessions, or want to, thus, it is important to look at these lower volume training regimes.

In the absence of resistance training but presence of creatine, Goltshalk et al $(2002,2008)$ showed significant improvements in dynamic leg strength [38,39], however due to the limited data available care should be taken comparing data in the absence of resistance training to that with training where more studies have been performed. However, the significant improvements reported in Chrusch et al. (2001) and Brose et al. (2003) suggest creatine supplementation could potentially reduce the number of falls and improve functional capacity of the elderly to a similar extent that is seen with resistance training alone [32,36].

\section{The effect of resistance training and/or creatine on muscular endurance and functional performance}

Poor muscular endurance is related to poorer mobility, which can significantly decrease quality of life in elderly adults [40], thus it is important to explore whether creatine supplementation may increase endurance. Chrusch et al. (2001) demonstrated that lower body muscular endurance significantly increased with creatine supplementation compared with placebo following resistance training, however no significant difference was observed in upper body endurance [32]. Tarnopolsky et al. (2007) investigated the effects of creatine supplementation combined with conjugated linoleic acid (CLA) during six months of resistance training [30]. Muscle endurance significantly improved upper body measurements for creatine and CLA supplementing subjects compared with placebo, and knee extension in the female creatine and CLA subjects only (Table 2) [30]. Although in this study both creatine and CLA were supplemented, it may be deduced that increases in muscular endurance were not due to CLA supplementation because the role of CLA has mostly been confined to reducing intra-abdominal fat in animal studies and there is no current evidence that it affects muscle [41].

A recent trial of creatine supplementation with and without resistance training revealed significant improvements in muscular endurance and strength in the upper body in subjects taking creatine supplementation and engaging in resistance exercise, over both placebo and resistance training alone [34]. In addition they showed that while there were improvements in lower limb muscular endurance over a non-exercising placebo, there was no further muscular benefit of creatine supplementation in comparison to undertaking resistance training without any creatine ingestion [34]. In agreement, Bermon et al. (1998) demonstrated that creatine supplementation did not enhance the effects of resistance training alone on muscular endurance [37]. Although the muscle groups 
assessed were similar, the measurement protocol used in Bermon et al. (1998) was different from other studies; subjects completed 12-RM (repetition maximum) with the maximum resistance possible, compared to the maximum number of continuous repetitions of the initially recorded 1-RM for each exercise [37] (Table 1). A limitation of this assessment protocol is that subjects knew they were completing 12 repetitions of a previously determined weight. Creatine supplementing subjects may have had the capacity to complete more repetitions, or placebo subjects may have pushed themselves to exhaustion. Furthermore, the selection process of the weight used was not described [37], therefore, there could be ambiguity between participants, a possible reason for the lack of improvement for muscular strength in this study.

\begin{tabular}{|c|c|c|c|c|c|c|c|c|c|c|}
\hline Author & $\begin{array}{c}\text { Amount of } \mathrm{Cr} \\
\text { supplemented per day }\end{array}$ & $\begin{array}{l}\text { No of } \\
\text { days }\end{array}$ & $\begin{array}{l}\text { Ad- } \\
\text { ditional } \\
\text { supple- } \\
\text { ments }\end{array}$ & $\begin{array}{l}\text { Bench } \\
\text { press } \\
(\mathrm{kg})\end{array}$ & $\begin{array}{l}\text { Leg } \\
\text { Press } \\
(\mathrm{kg})\end{array}$ & $\begin{array}{c}\text { Leg } \\
\text { extension } \\
\quad(\mathbf{k g})\end{array}$ & $\begin{array}{l}\text { Isometric } \\
\text { strength }\end{array}$ & $\begin{array}{l}\text { Muscular endurance (reps } \\
\text { of 1-RM) }\end{array}$ & $\begin{array}{l}\text { Body } \\
\text { mass } \\
(\mathrm{kg})\end{array}$ & $\begin{array}{l}\text { Body com- } \\
\text { position }\end{array}$ \\
\hline $\begin{array}{c}\text { Bermon } \\
\text { et al. } 1998 \\
{[37]}\end{array}$ & $\begin{array}{l}\text { LP: } 20 \mathrm{~g} / \text { day ( } 5 \text { days }) \\
\text { MP: } 3 \mathrm{~g} / \text { day ( } 47 \text { days })\end{array}$ & 52 & - & NS & NS & NS & - & NS & NS & $\begin{array}{c}\text { Lower LMV } \\
\quad=\mathrm{NS}\end{array}$ \\
\hline $\begin{array}{l}\text { Chrusch } \\
\text { et al. } 2001 \\
{[23]}\end{array}$ & $\begin{array}{c}\mathrm{LP}=0.3 \mathrm{~g} \cdot \mathrm{kg}^{-1} \text { body mass } \\
\text { ( } 5 \text { days). } \\
\mathrm{MP}=0.07 \mathrm{~g} \cdot \mathrm{kg}^{-1} \text { body mass } \\
(79 \text { days) Average Cr/day: } \\
\mathrm{LP} 26.4 \mathrm{~g} / \text { day, MP } 6.16 \mathrm{~g} / \\
\text { day. }\end{array}$ & 84 & - & NS & $\begin{array}{c}\text { SD } \\
(20 \mathrm{~kg})\end{array}$ & $\mathrm{SD}(3.3 \mathrm{~kg})$ & & $\begin{array}{c}\text { SD Leg press } \\
\text { (+ } 15 \text { reps); } \\
\text { SD Leg extension } \\
\text { (+ } 7 \text { reps); } \\
\text { NS Bench press }\end{array}$ & $\begin{array}{c}\mathrm{SD}(+3.0 \\
\mathrm{kg})\end{array}$ & $\begin{array}{l}\mathrm{LTM}=\mathrm{SD} \\
(+3.33 \mathrm{~kg})\end{array}$ \\
\hline $\begin{array}{c}\text { Brose } \\
\text { et al. } 2003 \\
{[36]}\end{array}$ & $5 \mathrm{~g} /$ day & 98 & - & NS & NS & NS & $\begin{array}{c}\text { SD Knee Exten- } \\
\text { sion }(+23.7 \%) ; \\
\text { SD Ankle dorsi- } \\
\text { flexion (+ } 15.6 \% \\
\text { males only) }\end{array}$ & - & $\begin{array}{c}\mathrm{SD}(+1.0 \\
\mathrm{kg})\end{array}$ & $\begin{array}{l}\mathrm{LTM}=\mathrm{SD} \\
(+1.3 \mathrm{~kg})\end{array}$ \\
\hline $\begin{array}{c}\text { Candow } \\
\text { et al. } 2008 \\
{[31]}\end{array}$ & $\begin{array}{l}0.1 \mathrm{~g} \cdot \mathrm{kg}^{-1} \text { on training days } \\
\text { only. Average } \mathrm{Cr} / \text { day: } 8.6 \mathrm{~g} \\
\text { (training days only). }\end{array}$ & 70 & $\begin{array}{l}0.3 \mathrm{~g} \\
\text { Pr.kg-1 }\end{array}$ & $\begin{array}{c}\mathrm{Cr}= \\
\mathrm{NS} \\
\mathrm{Cr}+\mathrm{Pr} \\
=\mathrm{SD} \\
(+10 \mathrm{~kg})\end{array}$ & - & - & - & - & $\begin{array}{c}\mathrm{Cr}=\mathrm{SD} \\
(+1.0 \mathrm{~kg}) \\
\mathrm{CrPr}= \\
\mathrm{SD}(+1.0 \\
\quad \mathrm{kg})\end{array}$ & $\begin{array}{c}\text { LTM: } \\
\text { Cr }=\text { SD } \\
(+1.5 \mathrm{~kg}) ; \\
\mathrm{CrPr}=\mathrm{SD} \\
(+2.6 \mathrm{~kg}) ; \\
\text { Muscle } \\
\text { thickness } \\
\text { Cr }=\text { SD (+ } \\
4.9 \%)\end{array}$ \\
\hline $\begin{array}{c}\text { Bemben } \\
\text { et al. } 2010 \\
{[27]}\end{array}$ & $\begin{array}{c}\mathrm{LP}=7 \mathrm{~g} \text { on training days } \\
\text { only ( } 14 \text { days). } \mathrm{MP}=5 \mathrm{~g} \\
\text { on training days only ( } 98 \\
\text { days). }\end{array}$ & 112 & $35 \mathrm{~g} \operatorname{Pr}$ & NS & & $\begin{array}{l}\mathrm{Cr}=\mathrm{NS} \\
\mathrm{Cr}+\mathrm{Pr}= \\
\mathrm{SD}(75 \%)\end{array}$ & - & - & - & $\begin{array}{c}\text { LTM: } \\
\mathrm{Cr}=\mathrm{NS} \\
\mathrm{CrPr}=\mathrm{NS}\end{array}$ \\
\hline $\begin{array}{l}\text { Tarnopol- } \\
\text { sky } \\
\text { et al. } 2007 \\
{[30]}\end{array}$ & $\mathrm{LP}+\mathrm{MP}=5 \mathrm{~g} /$ day & 168 & 6g CLA & NS & & NS & - & $\begin{array}{c}\text { NS Leg press; } \\
\text { SD Leg extension }(+7 \text { reps } \\
\text { females only); } \\
\text { SD Chest press }(+4 / 5 \text { reps } \\
\text { females/males); } \\
\text { SD Arm flexion }(+10 / 5 \\
\text { reps females } / \text { males })\end{array}$ & NS & $\begin{array}{c}\mathrm{LTM}=\mathrm{SD} \\
(+1.2- \\
1.3 \mathrm{~kg})\end{array}$ \\
\hline $\begin{array}{l}\text { Chilibeck } \\
\text { et al. } 2005 \\
{[23]}\end{array}$ & $\begin{array}{c}\mathrm{LP}=0.3 \mathrm{~g} . \mathrm{kg}^{-1} \text { body } \\
\text { mass ( } 5 \text { days). } \\
\mathrm{MP}=0.07{\mathrm{~g} . \mathrm{kg}^{-1} \text { body }} \\
\text { mass }(79 \text { days }) . \\
\text { Average Cr/day: } \mathrm{LP} \\
26.4 \mathrm{~g} / \text { day, } \mathrm{MP}: 6.16 \mathrm{~g} / \\
\text { day. }\end{array}$ & 84 & - & - & & - & - & - & - & $\begin{array}{c}\mathrm{BMD}=\mathrm{NS} \\
\mathrm{BMC} \mathrm{Arm} \\
=\mathrm{SD}(+3.2 \\
\%)\end{array}$ \\
\hline $\begin{array}{l}\text { Gualano et } \\
\text { al, 2014[34] }\end{array}$ & $\begin{array}{l}\mathrm{LP}=20 \mathrm{~g} / \text { day } \\
\mathrm{MP}=5 \mathrm{~g} / \text { day }\end{array}$ & 168 & - & $\begin{array}{c}\mathrm{SD} \\
(+10 \%)\end{array}$ & $\begin{array}{c}\mathrm{SD} \\
(+19.9 \%)\end{array}$ & - & - & - & - & $\begin{array}{l}\text { Appendicu- } \\
\text { lar } \mathrm{LM}=\mathrm{SD} \\
(+1.31 \%)\end{array}$ \\
\hline
\end{tabular}

Table 2. Summary table of key studies investigating the effect of creatine supplementation on muscular strength and power, and body composition, in elderly individuals who undertake resistance training. $\mathrm{Cr}=$ Creatine. $\mathrm{LP}=$ Loading phase. $\mathrm{MP}=$ maintenance phase. $\mathrm{CLA}=\mathrm{Conjugated}$ linoleic acid. $\mathrm{CrPr}=$ Creatine and Protein. $\mathrm{Pr}=$ Protein. $\mathrm{SD}=$ significant difference. $\mathrm{NS}=$ no significant difference. $-=\mathrm{Not}$ measured. $\mathrm{LMV}=$ limb muscular volume. $\mathrm{LTM}=$ lean tissue mass..BMC $=$ Bone mineral content. BMD = Bone mineral density. The values (e.g. $+3.3 \mathrm{~kg} / \%)$ are the improvements made after creatine supplementation and resistance training in comparison to placebo, and were considered to be significant at $\mathrm{p}=0.05$

Brose et al. (2003) and Tarnopolsky et al. (2007) investigated the effects of creatine supplementation in combination with resistance training on the functional performance of the elderly $[30,36]$. Both studies demonstrated that resistance training alone improved the ability of the elderly to carry out every day functional tasks, such as climbing stairs, however creatine supplementation did not significantly improve this performance. In contrast, Gualano et al (2014) showed that resistance trained subjects who ingested creatine managed a significant increase in timed-stand repetitions after training, which participants in the creatine alone group and resistance training group did not [34]. In the absence of resistance training, Golsthalk et al $(2002,2008)$ showed that creatine supplementation allowed subjects to deal with daily tasks $[38,39]$. 
Together, all these data suggest that stand alone resistance training and creatine supplementation both improve functional performance, however the additive effects is less clear: some studies shows an additive effect of creatine supplenetation with resistance training, whereas others do not. Having said that, creatine supplementation alongside resistance training does not reduce effects and thus should be recommended where possible to improve functional performance.

\section{The effect of resistance training and/or creatine on lean body mass (LBM)}

Resistance training has long been recommended for increasing lean body mass and muscular integrity and creatine supplementation has also been suggested to further enhance these effects [1]. Chrusch et al. (2001) and Brose et al. (2003) both showed significant increases in LBM following creatine supplementation and a resistance training programme [32,36]. Tarnopolsky et al. (2007) also demonstrated significant improvements in LBM following creatine and CLA supplementation [25]; the effect is unlikely to be due to CLA since CLA has not been shown to enhance LBM gains following resistance training [42]. More recently, Gualano et al. (2014) showed significant increases in appendicular lean mass when creatine supplementation was added to a long-term resistance training programme, beyond that of resistance training or creatine supplementation alone [34]. In contrast to these studies, Bermon et al. (1998) reported no significant changes in lower limb muscular volume for either placebo or creatine supplementing subjects in those undertaking resistance training [37], which is surprising since increases are expected following a resistance training programme, regardless of additional supplementation [43]. Candow et al. (2008) also did not report significant increases in LBM following a resistance and creatine supplementation period of 70 days [31]. However, this study used relatively low creatine levels for supplementation (average 8.6g/day on training days only). Furthermore, the total muscle thickness of both groups was also significantly improved with creatine supplementing subjects over placebo [31]. Work looking at the effects of creatine supplementation in the absence of resistance training on body mass and LBM is more variable, with some studies showing significant gains $[38,39,44]$, others non-significant increases [45,46] whilst Stout et al $(2007)$ saw no differences [47].

Currently, there is not enough significant evidence to confidently conclude that creatine supplementation increases LBM beyond that of the benefits well-known from a resistance training programme, and not to the same degree as a resistance programme can offer. This suggests that in terms of lean body mass, resistance training should still be recommended, if possible. However the recent results indicating additional increases in LBM in creatine supplementation with a long-term resistance programme, and the comparable increases in subjects taking creatine and subjecting undergoing resistance exercise [34] certainly suggests the need for further investigation to determine if a combination of treatments is fully necessary.

\section{The effect of resistance training and/or creatine on bone content and density}

It is has been previously demonstrated that strength training can increase bone mineral density and content [48]. The predominant hypothesised mechanism is that muscles exert strain on bones at their tendon attachment sites and this strain stimulates bone formation [49]. As creatine supplementation enhances the increases in muscle mass following resistance training [32], it may also be beneficial for increasing bone mineral content and/or density. This could have clinical importance in the elderly as the osteoporotic fractures are a significant cause of morbidity and mortality [50]. Chilibeck et al. (2005) subjected elderly individuals to a 12 week resistance training programme, with some subjects also consuming creatine supplementation [23]. Creatine supplementation significantly enhanced bone mineral content in the arms by $3.2 \%$ and this was significantly correlated with arm increases in LBM [23]. In contrast to this, Gualano et al. (2014) did not find any differences in either bone mass or serum bone markers following a creatine supplemented 24 week resistance training programme [34]. The authors explain that exercise may have less of an effect on bone mineral density on the elderly, particularly post-menopausal woman compared to the young, although they also suggest their study may be underpowered [34]. Considering the possibilities of creatine ingestion increasing muscle mass and stimulating bone formation [49], further studies should concentrate on investigating the potentials of this relationship to relieve the symptoms of osteoporosis, and determine if creatine supplements can mimic the effects of strength training on bone, as this sort of training may not be possible in patients with advanced osteoporosis.

\section{Conclusions and Future Perspectives}

There are several pieces of conflicting evidence in regards to creatine supplementation and its potential advantages in elderly subjects both in the presence and absence of resistance training. In regards to creatine supplementation without any resistance training programmes, studies by Gotlshalk et al. $(2002,2008)$ have revealed several positive results in both elderly females and males in increasing both lower body muscular strength and in their ability to perform everyday tasks [38,39]. However these results are far from being consistent across all studies [44], as is investigated in depth in a previous review [2].

Regular resistance training significantly enhances the strength and muscular endurance of the elderly [1]. If individuals are able, they should participate in such activities to increase their health and quality of life. However, not all aged individuals will be able to or willing to complete regular strength training, and in this situation creatine supplementation could potentially be a good substitute to maintain muscle strength and function, or used alongside to reduce the number of sessions required and maximise results [5]. Studies that have included creatine supplementation together with a resistance training programme have generated contrasting results. Creatine supplementation alone does lead to a significant increase in upper body strength [38,39], but data indicates that resistance training alone increases muscular strength to a greater extent than creatine supplementation without exercise. There also appears to be little benefit adding creatine supplementation to resistance training in increasing strength in the 
upper body [27,32,36,37], however improvements in lower limb muscular strength and functional performance have been demonstrated when the two protocols are combined [32]. The effect may be more profound in the larger groups of muscles found in the lower limb in comparison to the upper limb due to their increased ability to regenerate $\operatorname{PCr}$ [21].

Increasing muscular endurance in the elderly has been suggested to be an effective way to increase their quality of life and maintain a degree of independence. Current studies appear to show that increases in muscular endurance in creatine supplementing alongside resistance trained subjects were above that of placebo [30,32]. In addition, creatine appears to have an effect on increasing functional performance, both in the presence $[30,36]$ and absence $[38,39]$ of resistance training, suggesting that creatine may be an appropriate therapy for the elderly whether they are still physically active or not.

It should be remembered that there are both responders and non-responders to creatine supplementation, mainly dependent on skeletal muscle fibre type [51]. This could impact the potential beneficial effects of creatine in the elderly and may help explain the equivocal performance findings. Future work should assess participant's physiological profiles and sort them into responders and non-responders before beginning trials. This could be achieved by taking muscle biopsies before and after a short creatine supplementation period, and measuring total creatine content and cross-sectional area; alternatively muscle fibre type genetic profiling could be performed prior to trials.

The mechanism by which creatine elicits its effects requires further research as it is unlikely in some studies [38,39], given their short supplementation period, that substantial muscle hypertrophy has occurred. It is more likely that the effects of creatine are related to creatine kinase activity, providing enhanced energy production for greater muscular contraction $[9,12]$. Explorations of these mechanisms could provide more informed decisions about potential therapeutic and dosing strategies in the elderly.

Overall, it cannot be denied that the benefits of resistance training in the elderly on both muscle and bone health are substantial and well documented. However, despite evidence being inconsistent in some reports, creatine supplementation is clearly a useful supplement that has the potential to improve strength, endurance and quality of life in the elderly, even if taken in the absence of resistance training. Thus, to achieve the most beneficial results in improving overall quality of life in the elderly we would recommend where appropriate and achievable: resistance training and creatine supplementation $>>$ resistance training alone $>>$ creatine supplementation alone $>>$ no resistance training or creatine supplementation.

\section{References}

1. Candow DG (2011) Sarcopenia: current theories and the potential beneficial effect of creatine application strategies. Biogerontology $12: 273-81$.

2. Moon A, Heywood L, Rutherford S, Cobbold C (2013) Creatine supplementation: can it improve quality of life in the elderly without associated resistance training? Curr Aging Sci 6: 251-7.

3. Bemben MG, Lamont HS (2005) Creatine supplementation and exercise performance: recent findings. Sports Med 35: 107-25.

4. Wyss M, Kaddurah-Daouk R (2000) Creatine and creatinine metabolism Physiol Rev 80: 1107-213.

5. Kley RA, Vorgerd M, Tarnopolsky MA (2007) Creatine for treating muscle disorders. Cochrane Database Syst Rev.

6. Kushmerick MJ (1998) Energy balance in muscle activity: simulations of ATPase coupled to oxidative phosphorylation and to creatine kinase. Comp Biochem Physiol B Biochem Mol Biol 120: 109-23.

7. Saks VA, Ventura-Clapier R, Aliev MK (1996) Metabolic control and metabolic capacity: two aspects of creatine kinase functioning in the cells. Biochim Biophys Acta 1274: 81-8.

8. Sweeney HL (1994) The importance of the creatine kinase reaction: the concept of metabolic capacitance. Med Sci Sports Exerc $26: 30-6$.

9. Greenhaff PL, Bodin K, Soderlund K, Hultman E (1994) Effect of oral creatine supplementation on skeletal muscle phosphocreatine resynthesis. Am J Physiol 266: E725-30.

10. Branch JD (2003) Effect of creatine supplementation on body composition and performance: a meta-analysis. Int J Sport Nutr Exerc Metab 13: $198-226$.

11. Kreider RB (2003) Effects of creatine supplementation on performance and training adaptations. Mol Cell Biochem 244: 89-94.

12. Francaux M, Demeure R, Goudemant JF, Poortmans JR (2000) Effect of exogenous creatine supplementation on muscle PCr metabolism. Int J Sports Med 21: $139-45$.

13. Mihic S, MacDonald JR, McKenzie S, Tarnopolsky MA (2000) Acute creatine loading increases fat-free mass, but does not affect blood pressure, plasma creatinine, or CK activity in men and women. Med Sci Sports Exerc 32: 291-6.

14. Wilder N, Deivert RG, Hagerman F, Gilders R (2001) The Effects of Low-Dose Creatine Supplementation Versus Creatine Loading in Collegiate Football Players. J Athl Train 36: 124-9.

15. Willoughby DS, Rosene JM (2003) Effects of oral creatine and resistance training on myogenic regulatory factor expression. Med Sci Sports Exerc 35: 923-9.

16. Hespel P, Op’t Eijnde B, Van Leemputte M, Urso B, Greenhaff PL, et al. (2001) Oral creatine supplementation facilitates the rehabilitation of disuse atrophy and alters the expression of muscle myogenic factors in humans. J Physiol 536: 625-33.

17. Olsen S, Aagaard P, Kadi F, Tufekovic G, Verney J, et al. (2006) Creatine supplementation augments the increase in satellite cell and myonuclei number in human skeletal muscle induced by strength training. J Physiol 573: 525-34.

18. Hanssen KE, Kvamme NH, Nilsen TS, Rønnestad B, Ambjørnsen IK, et al. (2013) The effect of strength training volume on satellite cells, myogenic regulatory factors, and growth factors. Scandinavian J Med Sci in Sports 23: 728-39.

19. Kadi F, Schjerling P, Andersen LL, Charifi N, Madsen JL, et al. (2005) The effects of heavy resistance training and detraining on satellite cells in human skeletal muscles. J Physiol 558: 1005-12.

20. Gibson MC, Schultz E (1983) Age-related differences in absolute numbers of skeletal muscle satellite cells. Muscle Nerve 6: 574-80. 
21. Candow DG, Chilibeck PD (2005) Differences in size, strength, and power of upper and lower body muscle groups in young and older men. J Gerontol A Biol Sci Med Sci 60: 148-56.

22. Waters DL, Baumgartner RN, Garry PJ, Vellas B (2010) Advantages of dietary, exercise-related, and therapeutic interventions to prevent and treat sarcopenia in adult patients: an update. Clin Interv Aging 5: 259-70.

23. Chilibeck PD, Chrusch MJ, Chad KE, Shawn Davison K, Burke DG (2005) Creatine monohydrate and resistance training increase bone mineral content and density in older men. J Nutr Health Aging 9: 352-3.

24. Melov S, Tarnopolsky MA, Beckman K, Felkey K, Hubbard A (2007) Resistance Exercise Reverses Aging in Human Skeletal Muscle. PLoS ONE 2: e465.

25. Tarnopolsky MA, Safdar A (2008) The potential benefits of creatine and conjugated linoleic acid as adjuncts to resistance training in older adults. Appl Physiol Nutr Metab 33: 213-27.

26. Poortmans JR, Francaux M (2000) Adverse effects of creatine supplementation: fact or fiction? Sports Med 30: 155-70.

27. Bemben MG, Witten MS, Carter JM, Eliot KA, Knehans AW(2010) The effects of supplementation with creatine and protein on muscle strength following a traditional resistance training program in middle-aged and older men. J Nutr Health Aging 14: 155-9.

28. Smith SA, Montain SJ, Matott RP, Zientara GP, Jolesz FA (1985) Creatine supplementation and age influence muscle metabolism during exercise. J Appl Physiol 85: $1349-56$.

29. Harris RC, Soderlund K, Hultman E (1992) Elevation of creatine in resting and exercised muscle of normal subjects by creatine supplementation. Clin Sci (Lond) 83: 367-74.

30. Tarnopolsky M, Zimmer A, Paikin J, Safdar A, Aboud A, et al. (2001) Creatine monohydrate and conjugated linoleic acid improve strength and body composition following resistance exercise in older adults. PLoS One 2: e991.

31. Candow DG, Little JP, Chilibeck PD, Abeysekara S, Zello GA, et al. (2008) Low-dose creatine combined with protein during resistance training in older men. Med Sci Sports Exerc 40: 1645-52.

32. Chrusch MJ, Chilibeck PD, Chad KE, Davison KS, Burke DG (2001) Creatine supplementation combined with resistance training in older men. Med Sci Sports Exerc 33: 2111-7.

33. Tipton KD, Ferrando AA, Phillips SM, Doyle D, Wolfe RR (1999) Postexercise net protein synthesis in human muscle from orally administered amino acids. Am J Physiol 276: E628-34.

34. Gualano B, Macedo AR, Alves CR, Roschel H, Benatti FB, et al. (2014) Creatine supplementation and resistance training in vulnerable older women: a randomized double-blind placebo-controlled clinical trial. Exp Gerontol 53: 7-15.

35. Guralnik JM, Ferrucci L, Simonsick EM, Salive ME, Wallace RB (1995) Lower-extremity function in persons over the age of 70 years as a predictor of subsequent disability. N Engl J Med 332: 556-61.

36. Brose A, Parise G, Tarnopolsky MA (2008) Creatine supplementation enhances isometric strength and body composition improvements following strength exercise training in older adults. J Gerontol A Biol Sci Med Sci 58: 11-9.

37. Bermon S, Venembre P, Sachet C, Valour S, Dolisi C (1998) Effects of creatine monohydrate ingestion in sedentary and weight-trained older adults. Acta Physiol Scand 164: 147-55.

38. Gotshalk LA, Kraemer WJ, Mendonca MA, Vingren JL, Kenny AM, et al. (2008) Creatine supplementation improves muscular performance in older women. Eur J Appl Physiol 10: 223-31.

39. Gotshalk LA, Volek JS, Staron RS, Denegar CR, Hagerman FC (2002) Creatine supplementation improves muscular performance in older men. Med Sci Sports Exerc 34: 537-43..

40. Bautmans I, Njemini R, Predom H, Lemper JC, Mets T (2008) Muscle endurance in elderly nursing home residents is related to fatigue perception, mobility, and circulating tumor necrosis factor-alpha, interleukin-6, and heat shock protein 70. J Am Geriatr Soc 56: 389-96.

41. Sebedio JL, Angioni E, Chardigny JM, Gregoire S, Juaneda P, et al. (2001) The effect of conjugated linoleic acid isomers on fatty acid profiles of liver and adipose tissues and their conversion to isomers of 16:2 and 18:3 conjugated fatty acids in rats. Lipids 36: 575-82.

42. Kreider RB, Ferreira MP, Greenwood M, Wilson M, Almada AL (2002) Effects of conjugated linoleic acid supplementation during resistance training on body composition, bone density, strength, and selected hematological markers. J Strength Cond Res 16: 325-34.

43. Fielding RA (1995) The role of progressive resistance training and nutrition in the preservation of lean body mass in the elderly. J Am Coll Nutr 14: 587-94. 44. Rawson ES, Clarkson PM (2000) Acute creatine supplementation in older men. Int J Sports Med 21: 71-5.

45. Rawson ES, Wehnert ML, Clarkson PM (1999) Effects of 30 days of creatine ingestion in older men. European journal of applied physiology and occupational physiology 8: 139-44.

46. Wiroth JB, Bermon S, Andrei S, Dalloz E, Hebuterne X, et al. (2001) Effects of oral creatine supplementation on maximal pedalling performance in older adults. European journal of applied physiology 84: 533-9.

47. Stout JR, Sue Graves B, Cramer JT, Goldstein ER, Costa PB, et al. (2007) Effects of creatine supplementation on the onset of neuromuscular fatigue threshold and muscle strength in elderly men and women (64 - 86 years). J Nutr Health Aging 11: 459-64.

48. Ryan AS, Ivey FM, Hurlbut DE, Martel GF, Lemmer JT, et al. (2004) Regional bone mineral density after resistive training in young and older men and women. Scand J Med Sci Sports 14: 16-23.

49. Frost HM (1996) Perspectives: a proposed general model of the "mechanostat" (suggestions from a new skeletal-biologic paradigm). Anat Rec $244: 139-47$.

50. Johnell O, Kanis JA (2006) An estimate of the worldwide prevalence and disability associated with osteoporotic fractures. Osteoporos Int 17: 1726-33.

51. Syrotuik DG, Bell GJ (2004) Acute creatine monohydrate supplementation: a descriptive physiological profile of responders vs. nonresponders. J Strength Cond Res 18: 610-7.

52. Martini FH, Nath JL (2008) Fundamentals of Anatomy and Physiology. $8^{\text {th }}$ ed Pearson. 


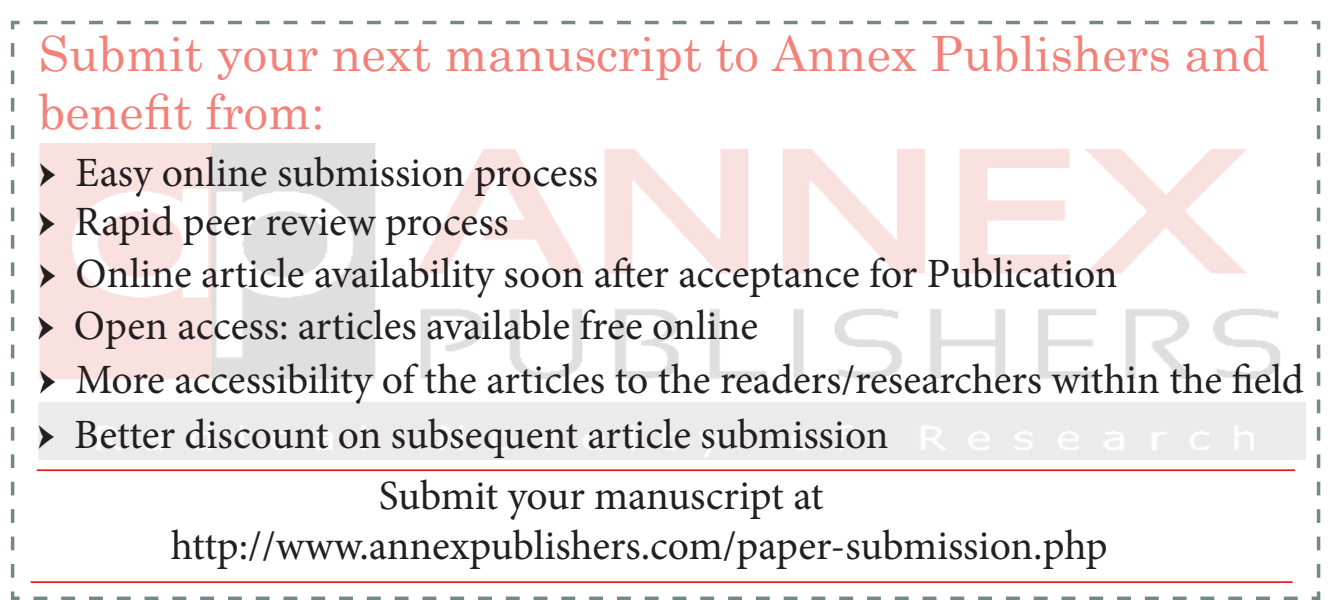

